\title{
Logical Pluralism and the Preservation of Warrant
}

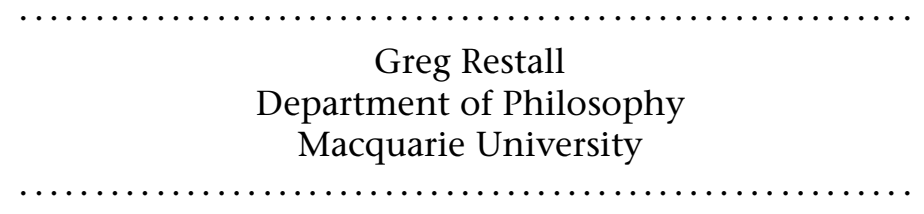

Version of February 29, 2000

This is a very rough draft. Please do not cite it.

\begin{abstract}
I defend logical pluralism against the charge that One True Logic is motivated by considerations of warrant transfer. On the way I attempt to clarify just a little the connections between deductive validity and epistemology.
\end{abstract}

\section{Pluralism}

I am a logical pluralist. I think that logical consequence is not just a manysplendoured thing, but that logical consequence is many different things. There is no one true logic but rather, many. Logic is a matter of "truth preservation in all cases" in the sense that

(V) An argument is (deductively) valid if and only if in any case in which all its premises are true, its conclusion is true too.

The variety of relations of logical consequence spring from the variety of appropriate ways to make the pretheoretic notion of a "case" precise. Classical predicate logic stems from taking cases to be the consistent complete worldlike entities of Tarski's model theory of classical logic. Constructive logic is given when you take cases to be possibly incomplete bodies of information or warrants or constructions that you might find in Kripke models for intuitionistic logic. Relevant logic is given when you take cases to be possibly incomplete or inconsistent (or both) ways the world might or might not be $[3,4,12]$.

I provide this very swift story to set the scene. I will not be arguing for logical pluralism here, except in the attenuated sense of defending it against some very particular objections. I will focus today on just one issue for logical pluralism: The connection between logic and warrant or justification. [[On the way, I will hopefully clarify this connection, and show that, instead of leading one away from pluralism, a proper understanding of the epistemology of inference actually supports pluralism with respect to logical consequence.]]

\section{The Dog and Disjunctive Syllogism}

Once there was a Dog, pursuing a Man down a bush track. The Dog follows the scent until she gets to a fork in the track. The dog believes that either the Man went down the left fork (call this proposition $A$ ) or the right fork (call this proposition B). So the Dog believes $A \vee B$. The Dog sniffs for a while down the left fork, and detects no scent. The Dog thus also believes $\sim A$ : the Man did not go down the left fork. Without hesitating to 
check for the scent down the right fork (and thus, without trying to find any independent evidence or warrant for B), the Dog continues her pursuit down the right fork in the track, inferring $B$, the claim that the Man has gone that way $[1,2,5]$. On this account of the Dogs' behaviour, the Dog is reasoning, and indeed, she seems to be reasoning well. She has used the inference disjunctive syllogism, which has the following form:

$$
\frac{A \vee B \sim A}{B}(D S)
$$

Proponents of relevant logics reject disjunctive syllogism, because when you combine it with certain unproblematic inferences (here, conjunction elimination and disjunction introduction) you can make the following implausible inference:

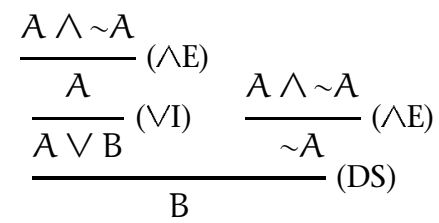

That is, disjunctive syllogism (together with conjunction elimination and disjunction introduction) leads to the odd conclusion that anything whatsoever (here B) follows from a contradiction (here $A \wedge \sim A$ ). That doesn't seem right (at least to relevant logicians) and so, disjunctive syllogism is rejected.

There is no doubt that there is something right about the relevantist's rejection of disjunctive syllogism, especially in the context of the inference of $B$ from $A \wedge \sim A$. When we assume $A \wedge \sim A$, it seems correct to deduce $A$ (and hence $A \vee B$ ) and $\sim A$, but to deduce from $A \vee B$ and $\sim A$ that it is $B$ that is true seems out of place. How could the reasoning go? $A \vee B$ is true, and $A$ isn't true, so it must be $B$ that makes $A \vee B$ true. But that's not right in this context. It's $A$ that makes $A \vee B$ true [6]. Of course, we're inconsistent about the truth of $A$, but that's simply because we were reasoning in the context of an inconsistent assumption.

My pluralist analysis of the appeal of this rejection of disjunctive syllogism is simple. We are admitting an inconsistent situation (or circumstance, or whatever you like to call these things) in which the contradiction $A \wedge \sim A$ is true, but in which $B$ is not. In this situation, the inference of disjunctive syllogism is blocked in the straightforward sense that the premises are true (for in this situation $A \vee B$ is true, given $A \wedge \sim A$, and $\sim A$ is true, also given $A \wedge \sim A$ ) but the conclusion is not true. It need not follow from this that I think that it is in any way possible for $A \wedge \sim A$ to be true. A pluralist must simply think that there are cases (in the sense of used to define logical consequence) in which contradictions are true. These cases or situations need not be possible any more than possible worlds need be actual.

An aside may help allay any fears about accepting the kind of impossibilia countenanced here: This acceptance of impossibilia is much less radical than it might seem, for proponents of classical predicate logic are also committed to cases in which impossibilities are true. For the inference from " $x$ is red" to " $x$ is coloured" is classically invalid, as there are models 
of classical predicate logic which allow objects into the extension of "red" which are not in the extension of "coloured." Models for predicate logic may involve impossibilities in much the same way as models for relevant logics. It is of course true that the behaviour of negation in an impossibility differs somewhat from its behaviour in what we might call "the actual world." The same is true for the behaviour of "is red" and "is coloured" in models for predicate logic. (A defence must be mounted to the effect that this variant behaviour is acceptable - in particular that it doesn't "change the subject" but is indeed providing an account of the behaviour of negation and not something else [9]. We have mounted such a defence elsewhere $[3,12]$.

As much as I find impossible situations important in the semantics of relevant logics, they are not the only way to understand the failure of disjunctive syllogism. The Scottish Plan of Stephen Read [10] takes the inference to fail because the conditional "if $A \vee B$ and $\sim A$ then $B$ " just fails to be true (on grounds of relevance) without there being any possible counterexample in which the premise is true and the conclusion false. The difference between Read's Scottish Plan and my pluralism is important, but not relevant to the task at hand. However you understand the failure of disjunctive syllogism, you need to give a plausible explanation of what is going on in the case of the Dog's reasoning.

The problem this poses for the pluralist (and the relevantist too) is straightforward one. Arguments about relevance (or constructivity) seem like mere quibbles when confronted with the Dog's reasoning. The classical acceptance of disjunctive syllogism seems to be completely correct. The Dog is not making a mistake by inferring $B$ from $A \vee B$ and $\sim A$. Given that her beliefs that $A \vee B$ and that $\sim A$ were warranted, then so is her belief that $B$. Conversely, if it turns out that she was somehow mistaken in her belief that $B$, this will be because one of her prior (but perhaps still justified) beliefs that $A \vee B$ and $\sim A$ was also mistaken. Her inference clearly seems a good one. The move from premises to conclusion seems to preserve any warrant the dog has for the premises into warrant for the conclusion too.

What can the proponent of relevant logics say about such a case? The relevantist like Read, for whom the One True Logic is a relevant one seem to be forced to say that the Dog is indeed making a mistake in inferring $B$ from her premises. The inference is invalid, and you make a mistake in stepping from premises to the conclusion. This does not mean that it is possible that the premises be true while the conclusion is false. Not at all. The relevantist may agree that it is impossible that the premises be true and the conclusion untrue - but the relevantist will go on to say that the impossibility of true premises and false conclusion is not a correct analysis of validity. More is needed for the validity of the argument, in particular the relevance of the premises to the conclusion.

Now, leaving aside the obvious concern that it seems clear that the premises are relevant to the conclusion in this case (what could be more relevant to $B$ than $A \vee B$ and $\sim A$ ?) the relevantist has more to worry about. Read agrees that it is impossible for the premises to be true and the conclusion false. The Dog will never (and indeed, can never) step from truth to falsity in making this inference. Why does this not count as validity? A technique of reasoning which is assured to never step from truth to falsity 
would at the very least seem to be useful for extending our body of knowledge, and to be the kind of thing logicians have attempted to develop and understand. Why this is not called validity seems unclear. Perhaps some account of relevance could be developed according to which inferences such as disjunctive syllogism make mistakes of relevance, but it is something else to say that there is no sense in which the Dog reasons well in using disjunctive syllogism. That is an altogether more difficult position to hold. I must leave it to relevantists such as Read to defend this position. ${ }^{1}$

The pluralist's position seems at least at the onset more simple. A pluralist can make the quite simple case that while the Dog's reasoning is not relevantly valid (as there are impossible situations in which the premises are true and the conclusion not true) it is valid in some other sense. One example is that it is classically valid, in the simple sense that it is impossible that the premises be true and the conclusion false. This too is a sense of validity worth the name, and the Dog is warranted in drawing the conclusion of B from its premises. The warrant of the premises "flows through" to the conclusion.

But now the pluralist has a problem not shared by the relevantist. We have a classical inference which preserves warrant in this sense. Will this not single out one logic as the logic which preserves warrant in just this sense in all reasoning situations? Will this not deserve to be called the One True Logic, since it seems best placed to guide reasoning? If warrant is preserved in cases such as the Dog's reasoning, then this seems to point to a logic stronger than relevant logics as appropriate for guiding and analysing reasoning. The initial appeal of pluralism might wear thin. ${ }^{2}$

In the rest of this paper I will defend pluralism against this objection, chiefly by showing that the issue of warrant preservation does not point the reasoner to a particular logic. Many logics can be used to guide and analyse reasoning, and many logics will play their part the transfer of warrant from premises to conclusions. There is not One True Logic of warrant transfer.

\section{Problem 1: Logical Omniscience}

Suppose, for the sake of the argument, that there is a logic of warrant transfer, and, for the sake of the argument, that it is something like classical predicate logic or one of its extensions. If this is the case, then for any argument from premises $X$ to conclusion $A$, if all of the premises in $\mathrm{X}$ are warranted (for some believer) so is the conclusion. Now, if just one premise (say B) is warranted then since all arguments from B to a tautology are valid, it will follow that all tautologies are warranted. But this cannot be correct. Not everyone has warrant for believing every tautology of classical predicate logic. Some tautologies are so complex that you only ought believe them when you have taken the time to read and understand what

\footnotetext{
${ }^{1}$ He does so in Chapter ?? of Relevant Logic [10], when he turns to another instance of disjunctive syllogism. The example is as follows: Socrates is either a man or a stone, Socrates is not a man, therefore Socrates is a stone. Read bites the bullet to the effect this argument is invalid, and that it would be a mistake to infer the conclusion from the premises. I almost cannot help but think that this is a reductio of his position.

${ }^{2}$ I thank Gary Kemp and Stephen Read for both putting this objection in discussion in February 2000.
} 
they might mean. Here is an example. Just when do you have a warrant for believing this? ${ }^{3}$

$$
(\exists x) \sim R x x \supset(\exists x) \sim((\forall y)(\forall z)(R x y \supset(R y x \wedge(\sim R y z \vee R x z)) \wedge(\exists y) R x y)
$$

Or in a simpler case, this?

$$
(\exists x)(F x \supset(\forall y) F y))
$$

Of course we need not deny that any tautology in classical predicate logic is potentially warranted, for if it is a tautology, it is provable, and any proof can at least in theory be surveyed and give reason for its conclusion. However, it does not follow that any for any tautology we actually possess a warrant for believing it. But this is what follows, at least if a logic of warrant transfer is something like classical logic. For any argument to a tautology is valid, and so, if warrant is transferred from premises to conclusion, simply take an argument with a warranted premises and a tautology as a conclusion. Since warrant is transferred to the conclusion, it follows that the tautology is warranted. This, of course, is an all too swift way of demonstrating the warrant attaching to tautologies.

It may be thought that we are biting off more than we need to chew in applying all of the validities of classical logic to the transfer of warrant. Perhaps it is simply the small, basic argument forms which preserve warrant: argument forms such as conjunction elimination, disjunction introduction and disjunctive syllogism. In these cases we do not take wild jumps from premises to irrelevant (but tautologous) conclusions. We take much more measured baby steps, from $A \wedge B$ to $A$, or from $A \vee B$ and $\sim A$ to $B$. Here it seems much more likely that warrant is preserved from premises to the conclusion.

If this is to be used as a defence of a logic such as classical logic as the logic of the preservation of warrant, then the baby steps used must add up to the whole logic. The collection of basic (warrant preserving) inferences must be a complete selection of rules so that any argument which is valid in the logic can be made up of a chain (or a tree) of these basic inferences. One candidate set of basic rules might be that of a natural deduction presentation of of the logic in question, with introduction and elimination rules which present the simple sense of each logical connective [8]. Plausibly, to know the meaning of the connective is to know how to use it in these basic inferences, so if anything preserves warrant these rules must.

This is an appealing picture, but it too must be flawed. If each of the baby steps in a proof preserves warrant, in the sense that if the premises have warrant so does the conclusion, then any argument, no matter how complex or convoluted, no matter how unsurveyably large, preserves warrant. The warrant provided for the premises filters down uninterrupted to

\footnotetext{
${ }^{3} \mathrm{I}$ am not sure that I am warranted in believing it. I got it by transforming the almost obvious tautology

$$
((\forall x)(\forall y)(R x y \supset R y x) \wedge(\forall x)(\exists y) R x y \wedge(\forall x)(\forall y)((R x y \wedge R y z) \supset R x z)) \supset(\forall x) R x x
$$

(to the effect that if $R$ is symmetric, without dead ends, and transitive, then it is also reflexive) to a non-obvious one by simple predicate logic transformations. However, I am not at all confident that I have not made a mistake along the way.
} 
the conclusion, passing through each rule along the way. If the warrant stops, it must stop at some inference, and this inference will fail to preserve warrant. ${ }^{4}$

Let me make this example more vivid. I take it that we have warrant for enough basic claims of arithmetic to do simple calculations involving addition and multiplication. From these basic claims, using logic alone we can prove all sorts of things. Andrew Wiles has shown [[Ref would be nice here]] that Fermat's Last Theorem can be proved. ${ }^{5}$ It seems that we are all warranted in believing that Fermat's Last Theorem is indeed true. However, we weren't so warranted before the proof was produced. Mere entailment is not enough to guarantee the preservation of warrant. If there is a logic of warrant preservation, it is nothing like classical predicate logic or any of its neigbours.

\section{Problem 2: Inconsistency and Warrants in Tension}

The reasons we have seen so far lead us away from the view that warrant preservation is tracked by classical predicate logic or anything like it. Any logic in which tautologies are entailed by anything whatsoever will give us warrants for all tautologies. Perhaps a relevant logic, in which tautologies need not follow from anything and everything, might do the trick.

This, however, seems also to not be the case. Epistemic agents like you and me not only fall below a logical ideal by not being logically omniscient, we also fail by having inconsistent beliefs, and even by having warranted inconsistent beliefs. I may have reason to believe $A$ and also, reason to believe a claim $B$ inconsistent with $A$. Lewis gives an example

I used to think that Nassau Street ran roughly east-west; that the railroad nearby ran roughly north-south; and that the two were roughly parallel. (By "roughly" I mean "to within $20^{\circ}$ ".) [7, page 436]

Here, Lewis believes three mutually inconsistent propositions. I take it that the example can be extended into one in which he has warrant for these three propositions. ${ }^{6}$ Each of the three can be warranted beliefs. If any false belief is ever warranted, and if any simple observational beliefs like these are warranted, then I take it that these three beliefs may be warranted, and may each be warranted together. If a belief must be consistent with the rest of an agent's beliefs in order to be warranted, then it seems to follow that nothing is ever warranted, as consistency of a belief set is so difficult to attain.

\footnotetext{
${ }^{4}$ You may notice the similarity with sorites paradoxes. Perhaps some case may be made to the effect that warrantedness is vague, and that there is no individual step where we pass from warranted premises to an unwarranted conclusion. [[I must think about this a little more, I suppose, but as I find epistemicist solutions to the sorites paradoxes more appealing anyway, I think I'm happy to sit with the view that there is a step from warrant to unwarrant. However, my opponent may not be so happy, so I need to think of what to say about this.]]

${ }^{5}$ He didn't prove it in simple arithmetic. He used many high powered techniques in abstract geometry and in particular, the theory of quadratic forms. It is unknown exactly what number theoretic claims are required to prove the theorem. If it is not proved in Peano Arithmetic, then it will be provable in some first-order extension of PA.

${ }^{6}$ I say "extended," because Lewis's discussion does not introduce the notion of warrant. He seeks merely to explore the notion of what might be "true according to his beliefs."
} 
So, in this example, Lewis has three warranted beliefs, A, B and C, such that the three are jointly inconsistent. Nothing forces us to conclude that the conjunction $A \wedge B \wedge C$ is one of Lewis's warranted beliefs. In fact, it seems implausible to suppose that the conjunction need be one of his beliefs, or that it has any warrant. If you were looking for a warrant for the belief that the world was inconsistent in just that way, you would need a lot more than simply the three warrants Lewis might have had for the beliefs $A, B$ and $C$. (Despite this hesitancy about the conjunction, there is still a sense that Lewis was committed to the inconsistent conjunction of his three beliefs. It is when Lewis realises that he is committed to such an inconsistency that he revises away one of the beliefs, or at least attempts to do so. $\left.{ }^{7}\right)$ This means that even simple logical inferences such as conjunction introduction

$$
\frac{A \quad B}{A \wedge B}(\wedge I)
$$

do not preserve warrantedness. We may have warrant for each of the premises of an inferences such as this, yet it may not be preserved to the conclusion. If there is anything like a logic of preservation of warrant, it will look nothing like traditional classical, constructive or relevant logics.

It is easy to see how this failure of simple rules comes about. What is desired is a logic of preservation of warrantedness. We wish to know that if we have warrants for the premises of an argument, we have a warrant for the conclusion too. If an argument has more than one premise, then the warrant for each premise might be in tension, and not combine to provide a warrant for the conclusion. The warrant Lewis might have for taking Nassau Street to run east-west was one thing (some experience of the street?), the warrant for taking the railroad to run north-south was another (some experience of the railroad?), and the warrant for taking them to be parallel a third (seeing them run together?). Taking these warrants together does not give you a warrant for the conjunction - it gives you instead a reason to reject at least one of the conjuncts.

The argument shows that despite having a reasons to believe $A, B$ and $C$, Lewis has no reason to believe $A, B$ and $C$ together. Each of the premises is warranted, but the conclusion is not. The logic of warrant preservation, if you wish to call it a "logic," is not classical, and it is not like any nonclassical logic I defend. Considerations of warrant preservation do not lead a logical pluralist to favour one system over another. They point in a very different direction again.

\section{The Dog Returns}

Now let us return to the case of the Dog. She infers $B$ from $A \vee B$ and $\sim A$. In this case, her warrant for the premises is preserved as warrant for the conclusion. We may agree that this step was a good one. But it does not follow that inferences of the form of disjunctive syllogism always preserve warrant. We may have a situation similar to Lewis's inconsistent triad of beliefs.

\footnotetext{
${ }^{7}$ I have defended a simple paraconsistent logic for the purpose of analysing truth according to a body of beliefs, or more simply, a believer's commitments. [11].
} 
Perhaps one kind of warrant leads me to believe $A \vee B$ on the basis of A. Perhaps I believe that Socrates was either an Athenian or a Spartan, on the basis that I have heard that he was an Athenian. Perhaps I also come to believe $\sim A$ (and to have warrant for such a belief) by some other route. Someone gives me reason to believe that Socrates was not an Athenian. Now if in this circumstance I still have warrant for my belief that he was Athenian (so I have warrant for $A$ and warrant for $\sim A$ ) then the inference fails to preserve warrant. There is no way that this difficult epistemic situation gives me any reason to believe that Socrates was a Spartan. Warrant here for $A \vee B$ and for $\sim A$ does not transfer to warrant for B. ${ }^{8}$ Disjunctive syllogism, like other truth preserving inferences, may fail to preserve warrant if the epistemic situation is right.

[[Something more about how relevant logics and classical logics both tell us something useful about the epistemic situation, though neither is tracking warrant in this case.]]

\section{Conclusion}

[[Extremely rough

We have gone some way in showing what considerations of preservation of warrant do not tell us. They do not force us away from a pluralist position into One True Logic, for considerations of preservation of warrant lead us away from logic altogether. What can we say positively about the connection between logic and the preservation of warrant? For this we need a coherent story of the nature of warrant and what it is for claims to be warranted. Different positions will give different conclusions at this point. Externalisms about warrant will tell us that a belief is warranted if it is acquired in the right kind of way. Given this account of warrant it will be clear that inference will play an important role, but validity will not track warrantedness in anything other than special cases. For an externalist story will tell us only what it is for a belief to be warranted, and it does not tell much about warrant for propositions not yet encountered or considered.

Internalisms about warrant might do a little more. They tend to look at logical relationships among beliefs and proof is an important part of internal justification and acquisition. Perhaps here we will find more to say about the relationship of validity and warrant preservation. The considerations we have seen so far, however, give us good cause to think that pluralism is in no way at threat, given a proper understanding of the role of logic in evaluating the preservation of warrant.]]

\section{References}

[1] Alan Ross Anderson and Nuel D. Belnap. Entailment: The Logic of Relevance and Necessity, volume 1. Princeton University Press, Princeton, 1975.

\footnotetext{
${ }^{8}$ If I replace the disjunction $A \vee B$ with a more robust conditional $\sim \mathrm{A} \rightarrow \mathrm{B}$ (particularly with a conditional possessing some counterfactual force) then warrant may well be preserved, since it is less likely that the warrant we have for $\sim A$ will undercut the warrant for $\sim A \rightarrow B$. Yet inference too might fail to be warrant preserving given the right epistemic conditions.
} 
[2] Alan Ross Anderson, Nuel D. Belnap, and J. Michael Dunn. Entailment: The Logic of Relevance and Necessity, volume 2. Princeton University Press, Princeton, 1992.

[3] JC BeAll AND GReg Restall. "Logical Pluralism". Under consideration, Year 2000 special issue on Logic of the Australasian Journal of Philosophy, 1999.

[4] JC Beall and Greg Restall. "Defending Logical Pluralism". In B. Brown AND J. Woods, editors, Logical Consequences. Kluwer Academic Publishers, forthcoming.

[5] Nuel D. Belnap and J. Michael Dunn. "Entailment and the Disjunctive Syllogism". In F. FløISTAD AND G. H. VON WRIGHT, editors, Philosophy of Language / Philosophical Logic, pages 337-366. Martinus Nijhoff, The Hague, 1981. Reprinted as Section 80 in Entailment Volume 2, [2].

[6] J. Michael Dunn. "Relevance Logic and Entailment". In Dov M. Gabbay AND FrAnZ GÜNTHNER, editors, Handbook of Philosophical Logic, volume 3, pages 117-229. Reidel, Dordrecht, 1986.

[7] DAVID LEWIS. "Logic for Equivocators". Noûs, 16:431-441, 1982.

[8] Dag Prawitz. Natural Deduction: A Proof Theoretical Study. Almqvist and Wiksell, Stockholm, 1965.

[9] Willard van Orman Quine. Philosophy of Logic. Prentice-Hall, Englewood Cliffs, NJ, 1970.

[10] Stephen ReAD. Relevant Logic. Basil Blackwell, Oxford, 1988.

[11] Greg Restall. "Ways Things Can't Be". Notre Dame Journal of Formal Logic, 39:583-596, 1997.

[12] Greg Restall. "Negation in Relevant Logics: How I Stopped Worrying and Learned to Love the Routley Star". In Dov GABbay AND HEInRICH WANSING, editors, What is Negation?, volume 13 of Applied Logic Series, pages 53-76. Kluwer Academic Publishers, 1999.

Greg Restall

Department of Philosophy, Macquarie University, Sydney, NSW 2109, AUSTRALIA.

Greg.Restall@mq.edu.au http://www.phil.mq.edu.au/staff/grestall/ 